\title{
Point: Routine Daily Physical Exams in Hospitalized Patients Are a Waste of Time
}

\author{
Adam Rodman, MD, MPH' ${ }^{1,2 *}$, and Shane Warnock, MD ${ }^{1}$
}

${ }^{1}$ Beth Israel Deaconess Medical Center, Boston, Massachusetts; ${ }^{2}$ Harvard Medical School, Boston, Massachusetts.

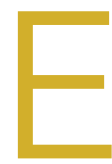

very day, physicians engage in an elaborate performance with their patients-the routine complete physical exam. We argue that this purportedly time-tested ritual is at best a waste of time, and at worst potentially harmful.

The modern physical exam evolved throughout the 19th century as the first diagnostic tool in a medical field that was rapidly transforming from its traditional roots to a modern scientific discipline. ${ }^{1}$ Despite the vast increase in diagnostic tools since then, the physical exam remains one of the most predictive. Several decades of investigation into the "evidence-based" physical exam have attempted to calculate the test characteristics of individual exam findings, confirming that the exam remains as useful a diagnostic tool today as it was for Laënnec or Osler. ${ }^{2}$

Performing a physical exam for the purposes of diagnosis and prognosis - not only on admission, but also on a daily basis to assess treatment response_-remains a fundamental part of a hospitalist's job. For example, a daily volume assessment, including cardiac auscultation for an $\mathrm{S}_{3}$, evaluation of the jugular venous pulse, and measurement of edema, is essential in managing patients with decompensated heart failure. However, when we stray from these diagnostic purposes, we are no longer using the exam as intended.

The physical exam most frequently performed in the hospital today is the so-called routine daily exam. Generally, this involves passing a stethoscope fleetingly across the chest and abdomen, perhaps with some additional palpation of the abdomen. Cranial nerves II through XII may also occasionally be checked. This routine exam-and by extension, the templated physical exams that fill hospitalists' documentation-not only lack an evidence base, but also are arguably harmful to patients. Such exams should not be part of a hospitalist's daily practice.

The most concerning aspect of a routine daily exam is that examination of an asymptomatic patient-for example, auscultation of the lungs of a patient admitted with lower extremity cellulitis-is fundamentally a screening rather than a diagnostic test. While little work has been done in the inpatient setting, decades of studies on outpatient screening exams demonstrate that very few of them are effective. ${ }^{3}$ For example,

*Corresponding Author: Adam Rodman, MD, MPH; Email: arodman@ bidmc.harvard.edu; Telephone: 617-754-4677; Twitter: @AdamRodmanMD.

Published online first August 18, 2021.

Received: March 13, 2021; Revised: June 19, 2021; Accepted: June 23, 2021

() 2021 Society of Hospital Medicine DOI 10.12788/jhm.3670 a review of commonly used exam maneuvers in wellness visits concluded that "for the asymptomatic, nonpregnant adult of any age, no evidence supports the need for a complete physical exam as traditionally defined," recommending against such popular maneuvers as lung and heart auscultation and peripheral pulse palpation. ${ }^{4}$ While the inpatient hospital medicine population has different characteristics that may warrant a routine exam, there is no evidence to support such practice.

It is often argued that the routine physical exam is "cheap" and "quick" and, therefore, should be performed regardless of evidence. While this is certainly true for many diagnostic physical exams, the literature suggests that there is no reason to think that a routine physical exam would be cost-effective. ${ }^{5}$ Even cost-effective screening physical exam tests, such as an outpatient nurse performing a 1-minute pulse palpation starting at age 55, have incremental costs measuring in the thousands of dollars. ${ }^{6}$ Furthermore, screening tests can have unexpected downstream effects that are both costly and associated with morbidity and mortality. ${ }^{7}$ For example, abdominal palpation of a "prominent" aorta can lead to imaging, where incidental findings can trigger procedures that may involve complications.

In addition to potentially adding more risk, the routine daily physical exam represents time that can be better allocated. Medical residents spend the vast majority of their day at the computer, while spending less than $10 \%$ of their time at the patient's bedside. ${ }^{8}$ Anything that takes up that valuable time, including a "routine exam," is time spent not talking to the patient, learning about their symptoms, their fears, and who they are as human beings.

It is also true that patients expect a physical exam to be performed, and that additional exam maneuvers, including potentially invasive exams, are associated with increasing patient satisfaction. ${ }^{9}$ However, these arguments miss much of the nuance of why patients have these expectations. Qualitative research suggests that much of a patient's desire for unnecessary tests or exams is actually their concern about a lack of validation or empathy from the physician, as well as general skepticism about evidence-based medical decision-making. ${ }^{10}$ Perhaps spending more face time with patients discussing their issues, rather than idle time performing routine maneuvers, would lead to even greater patient satisfaction.

Finally, one of the most popular arguments in defense of a routine physical exam is that the exam is a "sacred ritual" essential to the patient-physician relationship. ${ }^{11}$ However, this is an argument not supported by historical interpretation. The physical exam was developed as an explicitly diagnostic procedure in the early 19th century, while the primacy of the 
doctor-physician relationship dates back millennia, long before the development of the modern physical exam. Furthermore, modern historiography has identified the development of the physical exam as part of a movement to minimize the experience of the patient in their own disease, and to situate the physician as the ultimate source of knowledge about a patient's body rather than an attempt to strengthen a relationship. ${ }^{12}$

Ritual is indeed important, and the exam as currently practiced may indeed reinforce the physician-patient relationship. But we should also keep in mind what that relationship entails. Having full access to a patient's unclothed body and having the ability to perform invasive procedures are far beyond regular social norms - these are powerful diagnostic tools, yes, but they also serve to reinforce an imbalance of power in the relationship. Medical rituals have also changed dramatically over time. Modern evidence suggests that pulse palpation alone, the form of the exam that was dominant for millennia, has profound physiological effects even on critically ill patients. ${ }^{13}$ Rather than a diagnostic exam that has potential downstream cost implications and consumes valuable time from an encounter, we suggest a return to a more traditional ritual of physical touch: sitting at the patient's bedside, holding their hand, and speaking to them compassionately about their fears and hopes. This would be a far more valuable "routine" encounter to incorporate into the busy hospitalist's day.

\section{Acknowledgment}

The authors of this point-counterpoint thank Chris Smith, MD, and the members of the BIDMC Internal Medicine Residency Clinician Educator Track for thoughtful discussion around these topics.

Disclosures: The authors reported no conflicts of interest.

\section{References}

1. Laënnec RTH. De l'auscultation médiate ou Traité du Diagnostic des Maladies des Poumon et du Coeur fondé principalement sur ce Nouveau Moyen d'Exploration. Brosson \& Chaudé; 1819.

2. McGee S. Evidence-Based Physical Diagnosis. 4th ed. Elsevier; 2018.

3. Bloomfield HE, Wilt TJ. Evidence brief: Role of the annual comprehensive physical examination in the asymptomatic adult. VA Evidence Synthesis Program Evidence Briefs. US Department of Veterans Affairs; October 2011.

4. Oboler SK, LaForce FM. The periodic physical examination in asymptomatic adults. Ann Intern Med. 1989;110(3):214-226. https://doi.org/10.7326/00034819-110-3-214

5. Angus S. The cost-effective evaluation of syncope. Med Clin North Am. 2016;100(5):1019-1032. https://doi.org/10.1016/j.mcna.2016.04.010

6. Welton NJ, McAleenan A, Thom $\mathrm{HH}$, et al. Screening strategies for atrial fibrillation: a systematic review and cost-effectiveness analysis. Health Technol Assess. 2017;21(29):1-236. https://doi.org/10.3310/hta21290

7. Rothberg MB. The $\$ 50000$ physical. JAMA. 2020;323(17):1682-1683. https:// doi.org/10.1001/jama.2020.2866

8. Mamykina L, Vawdrey DK, Hripcsak G. How do residents spend their shift time? A time and motion study with a particular focus on the use of computers. Acad Med. 2016;91(6):827-832. https://doi.org/10.1097/ ACM.0000000000001148

9. Duan L, Mukherjee EM, Federman DG. The physical examination: a survey of patient preferences and expectations during primary care visits. Postgrad Med. 2020;132(1):102-108. https://doi.org/10.1080/00325481.2020.1713618

10. Kravitz RL, Callahan EJ. Patients' perceptions of omitted examinations and tests: a qualitative analysis. J Gen Intern Med. 2000;15(1):38-45. https://doi. org/10.1046/j.1525-1497.2000.12058.x

11. Costanzo $C$, Verghese $A$. The physical examination as ritual: social sciences and embodiment in the context of the physical examination. Med Clin North Am. 2018;102(3):425-431. https://doi.org/10.1016/j.mcna.2017.12.004

12. Jewson ND. The disappearance of the sick-man from medical cosmology, 1770 1870. Int J Epidemiol. 2009;38(3):622-633. https://doi.org/10.1093/ije/dyp180

13. Arnold $M H$, Komesaroff $P$, Kerridge I. Understanding the ethical implications of the rituals of medicine. Intern Med J. 2020;50(9):1123-1131. https://doi. org/10.1111/imj.14990

\section{Journal of Hospital Medicine}

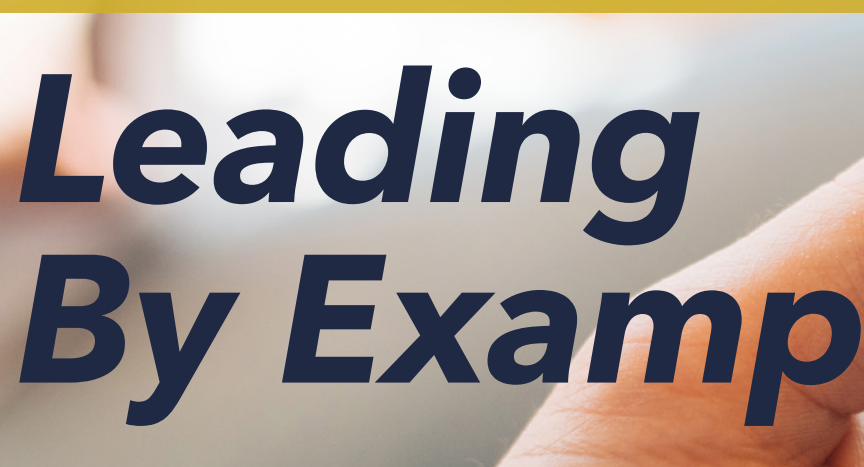

journalofhospitalmedicine.com 